\title{
Kalça Ağrısı Nedeniyle Tetkik Edilen Çocuklarda Manyetik Rezonans Görüntülemenin Yeri
}

\author{
Value of Magnetic Resonance Imaging in Children with Hip Pain
}

Ayşe Seçil EKŞiOĞLU', Seda KAYNAK ŞAHAP²

${ }^{1}$ Ankara Yıllırım Beyazıt Üniversitesi Tıp Fakültesi, Radyoloji Anabilim Dalı, Ankara, Türkiye

${ }^{2}$ Ankara Üniversitesi Tıp Fakültesi, Radyoloji Anabilim Dalı, Ankara, Türkiye

\section{Öz}

Amaç: Çocuklarda kalça ağrısı nadir olmayıp tanısal zorluk yaratabilmektedir. Akış şemalarında direkt grafiler önceliği alsa da erişebilirliğin olduğu merkezlerde Manyetik Rezonans Görüntüleme (MRG) klinisyenler tarafından ilk basamakta tercih edilebilmektedir. Bu çalışmada kalça ağrısı ile başvuran çocuklarda MRG bulgularının dağıımı ve MRG'nin tanı değeri araştırıldı. Direkt grafisi bulunan alt gruptaki konvansiyonel bulgularla karşılaştırıldı. Kalçada ağı ile başvuran çocuklar için protokol önerileri oluşturuldu.

Gereç ve Yöntemler: Ocak 2019 ile Mart 2020 tarihleri arasında hastanemize kalça ağrısı nedeniyle başvuran ve kalça MRG tetkiki yapılan 52 hasta (24 K /28 E; ortalama yaş: 9.4) çalışmaya dahil edildi. MRG bulguları retrospektif olarak değerlendirilerek kaydedildi. Hasta tanıları, klinik ve laboratuar bulgularının kombinasyonu kullanılarak doğrulandı. MRG'nin özgüllük, duyarlılık ve doğruluğu hesaplandı. Direkt grafileri de bulunan subgruptaki patolojik konvansiyonel bulgular incelendi.

Bulgular: MRG 52 hastadan 18'inde normal; 34 hastada patolojik olarak değerlendirildi. Klinik ve laboratuar bulgulara dayanarak 6 hasta yalancı negatif kabul edildi. Yaşları 7 ile 17 arasında değişen 7 hastada sakroileit bulguları saptandı. MRG'nin duyarlıı̆ı \%85, özgüllüğü \%100, doğruluk oranı ise \%88 olarak hesaplandı. Kontrast uygulanan 22 hastanın 8 'inde (\%36) tanıya ek katkı gözlendi. Hastaların üçte birinden (\%33) direkt grafi istenmemişti. Direkt grafi çekilen 35 hastanın da yalnızca 6'sında (\%17'si) patoloji tespit edilmiş olup kemiğe aitti.

Sonuç: MRG kalça ağrısı araştııırken yüksek duyarlıı̆ı nedeni ile erişimin kolay olduğu merkezlerde ilk basamak tetkik olarak tercih edilebilir. Direkt grafi istemleri belli kemik patolojilerle sınılandırımalıdır. Seçilmiş olgularda kontrast madde kullanımı ek bilgi sağlamaktadır. 7 yaşından büyük çocuklarda rutin kalça ağrısı protokolüne sakroiliak eklemlere yönelik sekansların eklenmesi önerilir.

Anahtar Sözcükler: Ağrı, Çocuk, Kalça, MR, MRG

ABSTRACT

Objective: Hip pain, which poses a diagnostic challenge, is common in children. In this study we aim to evaluate the diagnostic value of MRI in children with hip pain. Results are compared with radiographic findings. Imaging protocol suggestions are established.

(1)

0000-0002-7044-5270: EKȘioĞLU AS 0000-0003-1283-9543: KAYNAK ŞAHAP S
Çıkar Çatışması / Conflict of Interest: Tüm yazarlar adına, ilgili yazar çıkar çatışması olmadığını belirtir.

Etik Kurul Onayı / Ethics Committee Approval: Bu çalışma Helsinki Deklarasyonu IIlkelerine uygun olarak yapılmıştır. Çalıșma Dr. Sami Ulus Kadın Doğum, Çocuk Sağlığı ve Hastalıkları Eğitim ve Arașııma Hastanesi Klinik Araştırmalar Etik Kurulu tarafından 3 Haziran 2021 tarihinde E-21/06-177 sayilı etik kurul kararı ile onaylanmıştı.

Yazarların katkısı / Contribution of the Authors: EKȘiOĞLU AS: Araștırma ve/veya makalenin hipotezini veya fikrini olușturan, Sonuçlara ulașmak için planlama/metodoloji belirleme, Araștırma/çalıșmanın sorumluluğunu üstlenmek, ilerlemenin seyrini denetlemek, Hasta takibinde sorumluluk almak, ilgili biyolojik malzemelerin toplanması, veri yönetimi ve raporlama, deneylerin yürütülmesi, Sonuçların mantıksal olarak Yorumlanması ve sonuçlandırılması, Çalışma için gerekl literatür taramasında sorumluluk almak, Çalıșmanın bütününün veya önemli bölümlerinin yazımında sorumluluk almak, Yazım ve dilbilgisi dışında bilimsel olarak gönderilmeden önce makaleyi gözden geçirme. KAYNAK ŞAHAP S: Araștırma ve/veya makalenin hipotezini veya fikrini olușturan, Sonuçlara ulașmak için planlama/metodoloji belirleme, Araștırma/çalıșmanın sorumluluğunu üstlenmek, ilerlemenin seyrini denetlemek, Hasta takibinde sorumluluk almak, ilgili biyolojik malzemelerin toplanması, veri yönetimi ve raporlama, deneylerin yürütülmesi, Sonuçların mantıksal olarak Yorumlanması ve sonuçlandırılması, Calıșma için gereki literatür taramasında sorumluluk almak, Çalıșmanın bütününün veya önemli bölümlerinin yazımında sorumluluk almak, Yazım ve dilbilgisi dıșında bilimsel olarak gönderilmeden önce makaleyi gözden geçirme.

Atıf yazım şekli / How to cite : Ekșioğlu AS ve Kaynak Şahap S. Kalça Ağrısı Nedeniyle Tetkik Edilen Çocuklarda Manyetik Rezonans Görüntülemenin Yeri. Türkiye Çocuk Hast Derg 2021;15:513-517.
Yazıșma Adresi / Correspondence Address:

\section{Ayşe Seçil EKŞioĞLU}

Ankara Yıldırım Beyazıt Üniversitesi Tıp Fakültesi,

Radyoloji Anabilim Dalı, Ankara, Türkiye

E-posta: yucelsecil@yahoo.com
Geliş tarihi/ Received : : 29.09.2021 Kabul tarihi / Accepted : 08.11.2021 Elektronik yayın tarihi $\quad: 16.11 .2021$ Online published

DOI:10.12956/tchd.1001859 
Material and Methods: 52 children (24F/28 M; mean age: 9.4 years) who underwent an MR exam for hip pain were included. MR findings were retrospectively reavaluated and diagnosis were verified by using a combination of clinical and laboratory findings. Specificity, sensitivity and accuracy of MRI were calculated. Radiographic findings of the subgroup with X-rays were detected.

Results: MRI revealed normal findings in 18 and pathological findings in 34 patients. 6 cases were accepted as 'false negative' depending on clinical and laboratory findings. 7 sacroileitis were detected in patients with an age range of 7 to 17 years. The sensitivity, specificity and accuracy of MRI were calculated as $85 \%, 100 \%$ and $88 \%$ respectively. Contrast administration added diagnostic value in 8 of the 22 cases (36\%) with enhanced imaging. In 35 patients who underwent X-ray examination, only 6 patients (17\%) - all with bony lesions - had pathological findings.

Conclusion: MRI can be used as the first line imaging modality for hip pain in children in centers where it is easily accessable. X-rays shoud be limited to certain bony pathologies. IV contast administration adds value to MRI in selected cases. We suggest to add sacroiliac joint specific sequences to the MRI protocol for hip pain in children over 7 years.

Key Words: Pain, Child, Hip, MR, MRI

\section{Giriș}

Çocuk yaş grubunda kalça ağrısı nadir olmayan bir bulgu olup kısmen altta yatan etiyolojinin genișliği, kısmen de küçük çocukların kendilerini sözel olarak ifade edememeleri nedeni ile tanısal zorluk oluşturmaktadır (1-6).

Klinikte karşımıza kalça ağrısı olarak çıkan durumlar oldukça çeșitlilik göstermektedir. Kalça ekleminin lezyonları dışında diz, omurga ve sakroiliyak eklem patolojileri ve hatta akut apandisit gibi kas iskelet sistemi dışı hastalıklar da kalçaya yansıyan ağrı ile karşımıza çıkabilmektedir (1-6).

Çocuklarda kalça ağrısının nedenleri yaş gruplarına göre değişkenlik göstermektedir. Septik artrit, osteomyelit, travma ve neoplazik süreçler her yaş grubunda görülebilir. İnfant ve küçük çocuklar sıklıkla ağrı nedeni ile etkilenen bacağı kullanmada isteksizlik ve ağırlık vermekten çekinme şeklinde klinik bulgu verir ve bu yaş grubunda transient sinovit, tanı konmamış gelişimsel kalça displazisi ve istismar ile ilișkili patolojiler ayıııcı tanıda özellikle düşünülmelidir. Daha büyük çocuklar ise ağrıyı lokalize edebileceklerinden klinik yaklaşım daha kolaydır. 4-10 yaş arası grupta transient sinovit, Legg-Calve-Perthes hastalığı ve juvenil idiopatik artrit (JIA) ayıııcı tanıda ön sıralarda yer alır. Adölesan yaş grubunda kaymış kapital femoral epifiz ve spor yaralanmaları öncelikle düşünülmelidir (1-6). Tanıya ulaşmak için ayrıntılı öykü, fizik muayene, laboratuar bulgularının yanı sıra hemen her zaman radyolojik değerlendirme de gerekmektedir.

Klasik akış şemalarında özellikle infantlar ve küçük çocuklarda kalça ağrısında US sık kullanılan bir radyolojik modalite olmakla birlikte iki yönlü konvansiyonel radyografi halen ilk tercih görüntüleme yöntemidir $(1,3,4,6)$.

Ancak günümüzde büyük merkezlerde klinisyenler kimi zaman ilk basamak tetkikleri de atlayarak doğrudan MRG istemi yapma yoluna gidebilmektedirler (4).

Bunun yansıması olarak hastanemizde kalça ağrısı nedeni ile MRG'ye sıklıkla başvurulmaktadır. Bu çalışmada kalça ağrısı nedeni ile MRG yapılan çocuklarda bulgu sıklığı, yaş gruplarına göre dağıımı gözden geçirildi ve MRG'nin çocuklarda kalça ağrısında tanı değeri araştııılı. Yine kontrastı MRG incelemelerinde kontrast madde kullanımının tanıya kattığı ek değer incelendi. MRG yanı sıra direkt radyografi bulunan hastalarda direkt grafi bulguları da gözden geçirildi. Bu bilgiler ışığında kalça ağrısı ile başvuran çocuklar için görüntüleme protokolü açsısından önerilerde bulunuldu.

\section{GEREÇ ve YÖNTEMLER}

Çalışma Dr. Sami Ulus Kadın Doğum, Çocuk Sağlığı ve Hastalıkları Eğitim ve Araştırma Hastanesi Klinik Araştırmalar Etik Kurulu tarafindan 3 Haziran 2021 tarihinde E-21/06-177 sayılı etik kurul kararı ile onaylanmıştır.

Ocak 2019 ile Mart 2020 tarihleri arasında Dr. Sami Ulus Kadın Doğum, Çocuk Sağlığı ve Hastalıkları Eğitim ve Araştırma Hastanesinin pediatri polikliniklere kalça ağrısı nedeniyle başvuran ve radyoloji departmanına kalça MRG tetkiki istemi ile gönderilen 52 ardışık hasta çalışmaya dahil edildi.

MRG incelemeler 1.5 Tesla MR cihazı (Philips, Achiva) ile rutin kalça MRG protokolünde koronal plan T1 ve STIR sekanslar, aksiyel planda $\mathrm{T} 1$ yağ baskısız ve yağ baskll, T2 ve proton dansite sekanslar, sagittal plan proton dansite sekans alınarak gerçekleşirildi. Klinik istem nedenleri doğrultusunda kontrast madde (gadolinyum bazlı kontrast madde) kullanılan hastalarda aksiyel ve koronal plan yağ baskllı kontrastlı T1 sekanslar ve difüzyon inceleme rutin sekanslara eklendi.

Hastalar yașlarına göre 1-3 yaş, 4-10 yaș ve 11-18 yaș olmak üzere 3 gruba ayrıldı. Tüm hastaların medikal bilgileri, direkt grafileri ve MRG incelemeleri deneyimli bir pediatrik radyolog tarafindan retrospektif olarak değerlendirildi. Etiyolojik nedenler yaş gruplarına göre değerlendirildi.

Hasta tanıları elde olunan tüm klinik veriler, laboratuar, biyopsi ve görüntüleme bulgularının bir kombinasyonu kullanılarak literatürde ayrıntılı olarak tanımlanmış bulunan 'referans standardı' metodu ile doğrulandı (4). MRG'nin özgüllük, duyarllık ve doğruluğu hesaplandı.

Direkt grafisi bulunan hasta subgrubunda hangi patolojilerde direkt grafi bulgularının mevcut olduğu ve bu bulgulara MRG'nin 
katkıları gözden geçirildi. Kontrast madde kullanılan olgularda ise kontrast madde kullanımının tanıya katkısı değerlendirildi.

Araştırma verileri "SPSS (Statistical Package for Social Sciences) for Windows 22.0 (SPSS Inc, Chicago, IL)" aracilığıla bilgisayar ortamına yüklendi ve değerlendirildi. Tanımlayıcı istatistikler ortalama \pm standart sapma, frekans dağlımı ve yüzde olarak sunuldu.

\section{BULGULAR}

Çalışmaya 24 kIz (\%46) ve 28 erkek (\%54) çocuk dahil edildi. En küçük hasta 15 ay ve en büyük hasta ise 17 yaşında olup ortalama yaş $9.4 \mathrm{yll}$, ortanca yaş ise $10 \mathrm{ylld}$. 34 hastada MRG'de ağı kliniğini açıklayacak patolojik bulgular tespit edildi. 18 (\%35) hastada görüntüleme bulguları normal olarak değerlendirildi.

MRG'de bulgu saptanmayan ancak klinik ve hematolojik bulgularla (artmış sedimentasyon, lökositoz ya da her ikisi birlikte) ağrı kliniği ile birleștirildiğinde gerçek patoloji varı̆̆ını destekleyen 6 hasta mevcut olup bu vakalar yalancı negatif kabul edildi.

Tablo I yaş gruplarını ve bu gruplara göre patolojilerin dağlımını özetlemektedir.

0-3 yaş grubunda toplamda 1 hastada Perthes hastalığı saptandl.

4-10 yaş grubunda 5 hastada Perthes, 5 hastada sakroileit, 3 hastada Van-Neck Odelberg, 3 hastada enfeksiyöz sinovitmyozit-artrit, 2 hastada enflamatuar (reaktif sinovit ve JIA), 2 hastada (impingement ve trokantarik bursit), 1 hastada fraktür saptandl.

11-18 yaş grubunda 2 hastada sakroileit, 3 hastada travmatik patolojler (avulsiyon fraktürü ve sprain), 4 hastada enfeksiyöz nedenler (myozit, apse), 1 hastada Perthes, 1 hastada neoplazi (malign periferik sinir kllfı tümörü), 1 hastada trokantarik bursit saptandl.

23 hastada IV gadolinyum kullanılmıştı. Bir olguda kontrastı serilerde yaygın hareket artefaktları izlenmiş olup bu olgu dışlandı. 22 hasta üzerinden yapılan değerlendirmede 8 hastada kontrastlı sekansların tanıya ek katkısı gözlendi. Biyopsi ile malign periferik sinir kıllfı tümörü tanısı alan 1 hastada kitlenin solid özelliğini belirlemede, 3 olguda myozit zemininde gelişmiş apse odaklarını göstermede ve 4 olguda ise artrit bulgularına ilave olarak sinoviyal kalınlaşma ve sinovit bulgularını göstermede kontrast kullanımı yardımcı oldu (Resim 1).

Kalça ağrısının değerlendirilmesinde MRG incelemenin duyarlıı̆ı \%85, özgüllüğü \%100, doğruluk oranı ise \%88 olarak hesaplandı.

52 hastanın 35 'inde (\%67) direkt grafi mevcuttu. Hastaların üçte birinden (\%33) direkt grafi istenmemiști. Referans standardı ile patoloji olmadığı belirlenen 18 hastanın 10'unda direkt grafi çekilmiş olup bunların hepsinde bulgular normaldi. MRG'de patoloji saptanan 34 hastanın 24'ünde direkt grafi de çekilmiş olup sadece 6'sında patolojik bulgu saptandı. Bunlardan 4'ü Perthes, 2 olgu Van-Neck Odelberg tanısı almıştı. Direkt grafi çekilen 18 hastada MRG ile ağrıyı açıklayacak bir patoloji bulunduğu halde direkt grafi bulgusu saptanmadı. Direkt grafi çekilen tüm hastaların da yalnızca 6'sında (\%17'si) patoloji mevcuttu.

Perthes hastalı̆ı bulunan toplam 7 hastanın 5'inin direkt grafisi mevcut olup 4'ünde direkt grafi bulgusu izlendi. Direkt grafi ile tanı alan 1 hastada ise MRG'de bilateral Perthes bulguları mevcut iken direkt grafide tek taraflı etkilenim gözlenmekteydi.

Van-Neck Odelberg olgularında direkt grafide asimetrik iskiopubik sinkondroz izlenirken MRG'de eşlik eden kemik iliği ödeminin gözlenmesi tanıya katkı sağlamaktaydı (Resim 2).

7 hastada kalça incelemesi sırasında sakroileit bulguları saptandı ve tüm bu hastalarda yeniden sakroiliyak eklem MR incelemesi yapılması gerekti. Sakroileit tespit edilen çocukların 5'i erkek, 2'si kız olup yaşları 7 ile 17 arasında değişiklik göstermekteydi.

\section{TARTIŞMA}

Çocuklarda kalça ağrısı nadir olmayıp tanıda hemen her zaman görüntüleme yöntemlerine başvurulmaktadır. Ağrı öznel bir bulgu olup nedeninin organik olup olmadığını ayırt etmek önemlidir.

MR inceleme yüksek yumuşak doku rezolüsyonu, geniş field of view (FOV) ile görüntüleme yapılabilmesi, multiplanar görüntüleme özelliği, radyasyon içermemesi gibi özellikleri nedeni ile kalça ağrııının araştııımasında önemli bir modalitedir. MRG'nin duyarlıı̆ı kemik ve yumuşak doku patolojileri için oldukça yüksektir (1-4). Kontastı MRG kalça ağrısı nedeni ile her zaman gerekli olmasa da osteomyelit tanııının doğrulanmasında,

Tablo I: Yaş gruplarına göre kalça ağrısı ile ilişkili patolojilerin dağı̆ımı.

\begin{tabular}{l|c|c|c|c|c|c|c}
\hline \multicolumn{1}{|c|}{ Yaş Grubu } & Hasta Sayısı & Normal & Enfeksiyöz & Enflamatuar & Travmatik & Neoplastik & $\begin{array}{c}\text { Gelişimsel/ } \\
\text { Avasküler }\end{array}$ \\
\hline $\mathbf{1 - 3}$ yıl & 3 & 2 & 0 & 0 & 0 & 0 & 1 \\
$\mathbf{4 - 1 0}$ yıl & 29 & 8 & 3 & 9 & 1 & 0 & 8 \\
\hline $\mathbf{1 1 - 1 8}$ yıl & 20 & 8 & 4 & 3 & 3 & 1 & 1 \\
\hline Toplam & 52 & 18 & 7 & 12 & 4 & 1 & 10 \\
\hline
\end{tabular}



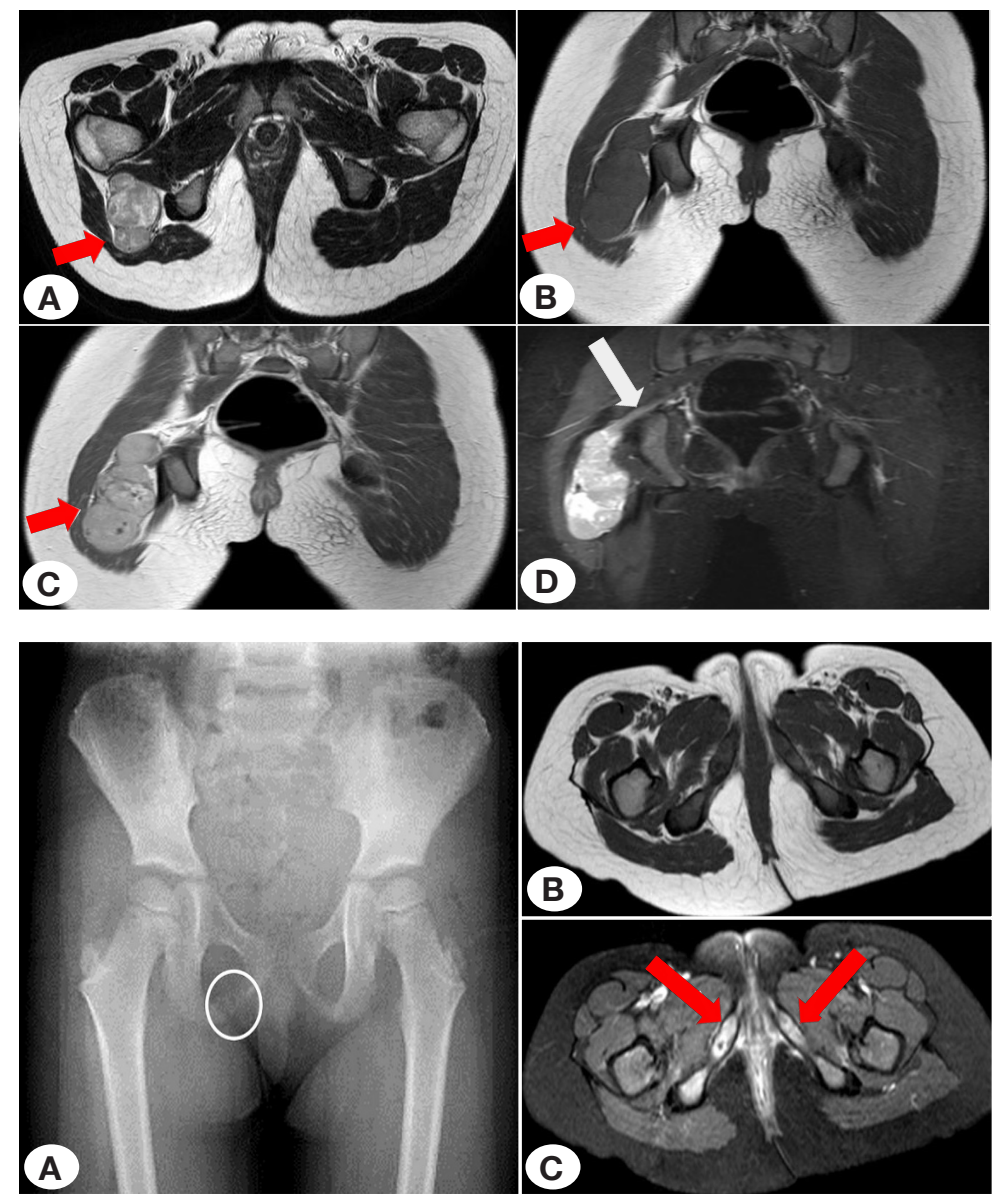

Resim 1: 13 yaşında kız hasta, aksiyel yağ baskısız T2AG'de (A) heterojen hiperintens ve koronal yağ baskısız T1AG'de (B) kasa göre hafif yüksek intensitede, koronal kontrastlı T1 AG'de (C) iyi kontrastlanan solid kitle (kırmızı oklar) izleniyor. Koronal yağ baskılı kontrastlı incelemede (D) kitlenin sinir ile ilişkisi de dikkati çekiyor (beyaz ok). Hastanın patoloji sonucu malign periferik sinir klıfı tümörü ile uyumlu olarak değerlendiriyor. malignensilerin yaygınlığının belirlenmesinde, belirsiz stres fraktürlerinin saptanmasında, erken dönem sekonder avasküler nekroz ya da Perthes hastalığı tanısında yararlıdır (3).

Tüm bu üstün özellikleri nedeni ile hastanemizde olduğu gibi ulaşımın kolay olduğu büyük merkezlerde klinisyenler çoğu zaman klasik akış şemalarında ilk basamak olarak tanımlanan direkt grafi (ve hatta US) incelemeyi atlayarak MRG istemi yapma yoluna gitmektedirler (4). MRG'nin yüksek yumuşak doku rezolüsyonundan yararlanabilmek, aynı zamanda zaman ve maliyeti de düșürmek amacıyla literatürde direkt grafi yerine ilk basamak olarak koronal STIR sekansın kullanılmasını öneren yayınlar da mevcuttur $(4,7,8)$. Ancak tek başına STIR sekanslar yüksek oranda patoloji varlığına ișaret edebilse de ancak tarama amacıyla kullanılabilmekte; lezyonların tanımlanabilmesi için tam bir MRG inceleme ile devam etmek gerekmektedir (4, 7-8).

Bizim çalışmamıza dahil edilen hastaların da üçte birinden yalnızca MRG istenmişti. Kalça ağrısı nedeni ile yapılan MRG bizim serimizde \%88 doğruluk, \%85 duyarlılık ve \%100 özgüllük göstererek oldukça başarılı bir yaklaşım olduğunu gösterdi. Bizim ulaștığımız bu bulgular daha önce literatürde tanımlanan değerler ile benzer özellik göstermekteydi (3-4,7). Patolojilerin yaş gruplarına göre dağılımı beklenen şekilde olup travmatik zedelenmeler adölesan dönemde, Perthes ise en çok 4-10 yaş grubunda izlendi.
IV kontrast madde enjeksiyonu yapılan hastaların sonuçları değerlendirildiğinde doğruluk, duyarlılk ya da özgüllük oranlarında değişiklik olmadığı ancak kontrast uygulamasının, değerlendirmeye alınan bu 22 hastadan 8'inde (\%36) tetkike ek değer kattığı görülmüștür. Kontrastı incelemede edinilen bilgiler 1 hastada malign lezyonun solid karakterini ortaya koymada, diğer olgularda (3 myozit, 4 artrit olgusu) ise apse varlığı ve sinovit bulgularını ortaya koyarak tedavi ve takip protokolünde değișikliğe yön vermiștir. Ancak burada kontrast madde enjeksiyonu yapılan olguların klinik muayene ve laboratuar ile enfeksiyon ya da kitle düşündüren seçilmiş olgular oldukları akılda tutulmalıdır.

Hasta grubumuzdaki 52 hastanın yalnızca üçte ikisinde direkt grafi çekildiği görülmektedir. Direkt grafisi bulunan 34 hastadan sadece 6'sında patolojik bulgu saptanmış olup bu seride direkt grafilerin kalça ağrısı tanısındaki duyarlıı̆ı oldukça düşük düzeydedir. Patolojik bulgu saptanan olgulardan 4'ü Perthes, diğer 2'si de Van Neck Odelberg hastalığı olup direkt grafilerin duyarlıı̆ı belirli kemik patolojilerinin tanısında daha yüksektir (9-12). Kalça ağrısı için çoğu merkezde iki yönlü direkt grafiler kullanılmakta olup 3-7 yaş arası çocuklarda AP pelvik radyografi için cilt dozu 0.049-0.06 arasında değișen oranlarda bildirilmiștir (13-15). Bu yaklaşık 3 akciğer grafisine eş doza karşılık gelmektedir. Ayrıca çoğu merkezde iki yönlü grafiler ilk basamak tetkiki oluşturduğundan bu dozu da en az iki ile çarpmak gerekir. 
MRG aslen patolojik olduğu halde direkt grafi ile bulgu saptanamayan 18 hastada lezyonları ortaya koymaktadır. Bunlar büyük oranda yumuşak doku, eklem lezyonları olmakla birlikte kemik lezyonlarında da duyarılığı artırmaktadır. Örneğin direkt grafi ile unilateral Perthes tanısı alan bir hastada diğer eklemde de erken dönem Perthes varlığı yine MRG ile ortaya konmuştur.

Inceleme sırasında karşımıza çıkan ilginç bir diğer bulgu da kalça ağrısı ile başvuran çocuklarda azımsanmayacak sıklıkta sakroileit tespit edilmesidir. Kalça ağrısı nedeni ile taranan 52 olgudan 7'sinde (yaklaşık \%14); patoloji tespit edilen 34 olgunun \%20'sinde tek ya da iki taraflı sakroileit izlenmiştir. Bu olguların çoğunluğunu erkek hastalar oluşturmakta olup bu seride 7 yaş altı olgu bulunmamaktadır. Sakroileit tanısı MRG incelemenin geniş FOV ile taramaya izin vermesinin sonucunda tanı alabilmektedir. Bu hasta grubunda rutin kalça protokolü ile sakroileit tanısı alan hastalar bu ekleme yönelik ek sekanslarla daha ayrıntıı olarak değerlendirildi. Kalça ağrısının zorlu bir tanı olmasının nedenlerinden biri çeşitli alanlardan kalça eklemine yansıyan ağrıarın da ayıııcı tanıya girmesi olup çalısmamızda bunlardan en sık rastlanılanı sakroileit olarak öne çıkmıştır (16).

Çalışmamızın en önemli limitasyonu retrospektif özellikte oluşu olup klinik ve fizik muayene bulgularına sistemde kayıtlı olduğu kadarı ile ulaşılabilmiş olmasıdır.

\section{SONUÇ}

Direkt grafilerin; Perthes, kaymış femur başı epifizi, osteoid osteoma gibi ağrıya neden olabilecek bazı kemik patolojlerinde yardımı olmakla birlikte kalça ağrısına neden olan tüm etyolojiler düşünüldüğünde duyarllık ve özgüllüğü düşüktür.

MR incelemeler yüksek yumuşak doku çözünürlügü ile kalça ağrısı araştıııırken duyarlı̆̆ı en yüksek yöntem olup yansıyan ağrıya neden olan patolojlerin de aydınlatımasına yardımcı olacaktır. Seçilmiş olgularda kontrast madde eklenmesi ek bilgi sağlamaktadır. 7 yaşından büyük çocuklarda rutin kalça MRG protokolüne sakroiliak eklemlere yönelik koronal STIR sekansın eklenmesinin de uygun olacağı görüşündeyiz.

\section{KAYNAKLAR}

1. Jain N, Sah M, Chakraverty J, Evans A, Kamath S. Radiological approach to a child with hip pain..Clin Radiol 2013 Nov;68:116778.

2. Bartoloni A, Aparisi Gómez MP, Cirillo M, Allen G, Battista G, et al. Imaging of the limping child. Eur J Radiol 2018;109:155-70.

3. Sarwar ZU, DeFlorio R, Catanzano TM. Imaging of nontraumatic acute hip pain in children: multimodality approach with attention to the reduction of medical radiation exposure. Semin Ultrasound CT MR 2014;35:394-408

4. White PM, Boyd J, Beattie TF, Hurst M, Hendry GM. Magnetic resonance imaging as the primary imaging modality in children presenting with acute non-traumatic hip pain Hendry. Emerg Med J 2001;18:25-29.

5. Tal Laor. Hip and groin pain in adolescents. Pediatr Radiol 2010; 40:461-7.

6. Milla SS, Coley BD, Karmazyn B, Dempsey-Robertson ME, Dillman JR, Dory CE, et al. ACR Appropriateness Criteria® limping child-ages 0 to 5 years. J Am Coll Radiol 2012;9:545-53.

7. Forbes-Amrhein MM, Marine MB, Wanner MR, Roth TD, Davis JT, Ravi AK, et al. JOURNAL CLUB: Can Coronal STIR Be Used as Screening for Acute Nontraumatic Hip Pain in Children? AJR Am J Roentgenol 2017;209:676-83.

8. Khoury NJ, Birjawi GA, Chaaya M, Hourani MH. Use of limited MR protocol (coronal STIR) in the evaluation of patients with hip pain. Skeletal Radiol 2003;32:567-74.

9. Özen A, Sanal HT, Yıldız C. Legg-Calvé-Perthes hastalığında MR görüntüleme MR imaging in Legg-Calvé-Perthes disease. TOTBID Dergisi 2017; 16:17-23.

10. Mixa PJ, Segreto FA, Luigi-Martinez H, Diebo BG, Naziri Q, Kolla S, et al. van Neck-Odelberg Disease: A 3.5-Year Follow-Up Case Report and Systematic Review Surg Technol Int 2017;31:365-73.

11. Peck D. Slipped capital femoral epiphysis: diagnosis and management. Am Fam Physician 2010; 82:258-62.

12. Mettler FA Jr, Huda W, yoshizumi TT, Mahesh M. Effective Doses in Radiology and Diagnostic Nuclear Medicine: A Catalog. Radiology 2008: 254-63.

13. Bomer J, Klerx-Melis F, Holscher HC. Painful paediatric hip: frogleg lateral view only. Eur Radiol 2014;24:703-8.

14. Mooney JF 3rd, Murphy RF. Septic arthritis of the peditric hip: update on diagnosis and treatment. Curr Opin Pediatr 2019;31:7985.

15. Ekşioğlu AS, Uner Ç. Pediatricians' awareness of diagnostic medical radiation effects and doses: are the latest efforts paying off? Diagn Interv Radiol 2012;18:78-86.

16. Şahin Onat Ş. Eklem Ağrılı Çocuklarda Tanısal Yaklaşım Diagnostic Aproach To Painful Joints With Children. Abant Med J2014;3: $201-$ 9. 